\title{
Interaction of Mycoplasma genitalium with host cells: evidence for nuclear localization
}

Correspondence

Joel B. Baseman

baseman@uthscsa.edu

Received 23 May 2008

Revised 30 June 2008

Accepted 1 July 2008
Priscilla M. Ueno, ${ }^{3}$ Jorge Timenetsky, ${ }^{3}$ Victoria E. Centonze, ${ }^{2}$ Jimmy J. Wewer, ${ }^{2}$ Marianna Cagle, ${ }^{1}$ Murry A. Stein, ${ }^{1}$ Manickam Krishnan ${ }^{1}$ and Joel B. Baseman ${ }^{1}$

\author{
${ }^{1}$ Department of Microbiology and Immunology, The University of Texas Health Science Center at \\ San Antonio, 7703 Floyd Curl Drive, San Antonio, TX 78229, USA \\ ${ }^{2}$ Department of Cellular and Structural Biology, The University of Texas Health Science Center at \\ San Antonio, 7703 Floyd Curl Drive, San Antonio, TX 78229, USA \\ ${ }^{3}$ Departamento de Microbiologia, Instituto de Ciencias Biomedicas, Universidade de Sao Paulo, Rua \\ Professor Lineu Prestes, 1374 Sao Paulo, Brazil
}

\begin{abstract}
Mycoplasma genitalium $(\mathrm{Mg})$ is a mollicute that causes a range of human urogenital infections. A hallmark of these bacteria is their ability to establish chronic infections that can persist despite completion of appropriate antibiotic therapies and intact and functional immune systems. Intimate adherence and surface colonization of mycoplasmas to host cells are important pathogenic features. However, their facultative intracellular nature is poorly understood, partly due to difficulties in developing and standardizing cellular interaction model systems. Here, we characterize growth and invasion properties of two Mg strains (G37 and 1019V). Mg G37 is a high-passage laboratory strain, while $\mathrm{Mg} 1019 \mathrm{~V}$ is a low-passage isolate recovered from the cervix. The two strains diverge partially in gene sequences for adherence-related proteins and exhibit subtle variations in their axenic growth. However, with both strains and consistent with our previous studies, a subset of adherent Mg organisms invade host cells and exhibit perinuclear targeting. Remarkably, intranuclear localization of $\mathrm{Mg}$ proteins is observed, which occurred as early as 30 min after infection. Mg strains deficient in adherence were markedly reduced in their ability to invade and associate with perinuclear and nuclear sites.
\end{abstract}

\section{INTRODUCTION}

Mycoplasma genitalium $(\mathrm{Mg})$ is an important human mollicute first isolated in 1981 from urethral exudates of men diagnosed with non-gonoccocal urethritis (Tully et al., 1981). One of the original isolates, G37, has become the type strain and its genome is fully sequenced. This species possesses the smallest known genome among prokaryotes capable of axenic growth, encoding only 484 proteins (Fraser et al., 1995). The reduced genome permits limited catabolic activities, thereby rendering $\mathrm{Mg}$ highly fastidious and dependent on biosynthetic precursors and nutrients supplied in vitro or in vivo.

Numerous additional studies have determined that $\mathrm{Mg}$ is a worldwide cause of urethritis and plays a role in cervicitis, pelvic inflammatory disease and tubal infertility (Stein \& Baseman, 2006). Mg-mediated urogenital infection increases the likelihood of symptomatic infection when

Abbreviations: $\mathrm{BCA}$, bicinchoninic acid; $\mathrm{CCU}$, colour-change units; LSCM, laser scanning confocal microscopy; Mg, Mycoplasma genitalium; Mp, Mycoplasma pneumoniae; Mpen, Mycoplasma penetrans. compared to colonization by Chlamydia trachomatis (Falk et al., 2004). In addition, $\mathrm{Mg}$ persists in the urogenital tract following antibiotic usage (Cohen et al., 2007; TaylorRobinson et al., 2004; Wikstrom \& Jensen, 2006).

The initial Mg-host cell adherence event is considered critical to colonization and establishment of human urethritis (Mernaugh et al., 1993). Specific Mg adhesins are surface-exposed, yet linked to an internal cytoskeleton apparatus that constitutes the unique apical tip or terminal organelle. Two major adherence-associated, highly immunogenic proteins, P140 and P110, encoded by the MG191 and MG192 genes, respectively, mediate $\mathrm{Mg}$ binding to host determinants (Baseman et al., 2004; Wang et al., 1997). Importantly, these mycoplasma proteins appear to undergo antigenic variation, and their absence markedly reduces cellular colonization (Baseman \& Tully, 1997; Stein \& Baseman, 2006).

Following adherence of $\mathrm{Mg}$ to cultured mammalian cells, internalization of a subset of mycoplasmas occurs (Baseman et al., 1995; Dallo \& Baseman, 2000; Jensen et al., 1994; Mernaugh et al., 1993). The biological 
relevance of this observation is further reinforced by the fact that $\mathrm{Mg}$ organisms are detected within cervical and vaginal epithelial cells from infected patients (Blaylock et al., 2004). However, the kinetics of Mg internalization has not been determined, and details of the subcellular locale occupied by these intracellular mycoplasmas are deficient. The possibility that $\mathrm{Mg}$ establishes an intracellular niche is especially compelling in the context of the clinical findings of chronic infections and mycoplasma persistence after antibiotic treatments (Stein \& Baseman, 2006). However, it is not clear if the current in vitro model systems used to examine $\mathrm{Mg}$ interactions with host cells are suitable to replicate events occurring during disease. In the past, $\mathrm{Mg}-$ host cell studies have exclusively utilized the laboratory high-passage strain Mg G37 with infected tissue culture cells that did not represent the in vivo niche where the strains were originally recovered.

To this end, we initiated studies to compare the interaction of type strain Mg G37 with a representative, freshly isolated and low-passage clinical variant designated 1019V (Musatovova et al., 2006) using human cell lines of urogenital origin. This focus provided additional insights into potential cellular compartments in which $\mathrm{Mg}$ resides.

\section{METHODS}

Growth curve of Mg. In order to establish the growth patterns of multiple-passage reference strain Mg G37 (ATCC 33530) and lowpassage (fifth broth transfer) $\mathrm{Mg} 1019 \mathrm{~V}$ strain isolated in our laboratory, each strain was grown in $150 \mathrm{~cm}^{2}$ tissue culture flasks containing $100 \mathrm{ml} \mathrm{SP}-4$ medium at $37^{\circ} \mathrm{C}$ for $72 \mathrm{~h}$ and harvested by scraping surface-attached cells into $10 \mathrm{ml}$ fresh SP-4 medium. Cells were divided into ten $1 \mathrm{ml}$ aliquots, and each aliquot was inoculated into $100 \mathrm{ml}$ fresh SP-4 medium in $150 \mathrm{~cm}^{2}$ tissue culture flasks and incubated aerobically at $37^{\circ} \mathrm{C}$. The first culture was collected after $24 \mathrm{~h}$ incubation, and the remaining cultures were harvested every $12 \mathrm{~h}$ for 4 sequential days. At each time interval, $\mathrm{Mg}$ surface-attached cells were scraped into $10 \mathrm{ml}$ fresh SP-4 medium and centrifuged at $14000 \mathrm{~g}$ for $30 \mathrm{~min}$ at $4{ }^{\circ} \mathrm{C}$. Mycoplasma pellets were washed twice in $\mathrm{PBS}$, suspended in $2 \mathrm{ml} \mathrm{PBS}$, passed repeatedly through 25-gauge needles to disperse large clumps, and analysed by $\mathrm{OD}_{600}$, the bicinchoninic acid (BCA) assay for total protein content (Pierce), colour-change units (CCU), which are directly related to the titre of viable, metabolically active mycoplasmas as determined by colonyforming units (Razin \& Tully, 1983), and real-time-PCR (Blaylock et al., 2004). All measurements were performed in triplicate and a minimum of two separate times.

DNA isolation and real-time PCR. Genomic DNA was isolated from Mg strains G37 and 1019V using the Easy-DNA kit (Invitrogen). The concentration of genomic DNA was determined by measuring absorbance at 260 and $280 \mathrm{~nm}$. Mg G37 and 1019V genome numbers were quantified using the Mg gyrA gene as target (Blaylock et al., 2004). Real-time PCR was performed in triplicate using TaqMan chemistry (Applied Biosystems).

Chromosomal DNA of Mg reference strain G37 was serially diluted (from $10^{7}$ to 1 genome per reaction) to establish standard curves (Blaylock et al., 2004). All reactions were performed in triplicate using TaqMan Universal PCR Master Mix, a $0.5 \mu \mathrm{M}$ concentration of primers and a $0.2 \mu \mathrm{M}$ concentration of probe as suggested by the manufacturer (Applied Biosystems). Amplification conditions con- sisted of $50{ }^{\circ} \mathrm{C}$ for $2 \mathrm{~min}, 95{ }^{\circ} \mathrm{C}$ for $10 \mathrm{~min}$, and 40 cycles of $95{ }^{\circ} \mathrm{C}$ for $15 \mathrm{~s}$ and $60^{\circ} \mathrm{C}$ for $1 \mathrm{~min}$ (ABI PRISM HP7900 SDS, Applied Biosystems).

Human HeLa and EM42 cell cultures. HeLa cervical epithelial carcinoma cell line (ATCC CCL-2) and the non-carcinoma endometrial cell line EM42 were used in co-incubation studies with Mg. EM42 cells were established from benign proliferative endometrium (Desai et al., 1994) and exhibit normal chromosomes and epithelial cell morphology, which, combined with their positive staining for cytokeratin and glycodelin, confirm their epithelial phenotype (Poddar et al., 1998). EM42 cells were cultivated in RPMI 1640 supplemented with $5 \%(\mathrm{v} / \mathrm{v})$ fetal bovine serum and $2 \mathrm{mM} \mathrm{L}-$ glutamine (Gibco). HeLa cells were cultivated in Eagle's Minimum Essential Medium (Gibco) supplemented with $10 \%$ fetal bovine serum and $2 \mathrm{mM}$ L-glutamine and Earle's BSS (Gibco). All cell culture working stocks were grown in a $5 \% \mathrm{CO}_{2}$ atmosphere at $37{ }^{\circ} \mathrm{C}$ and routinely certified free of mycoplasma contamination using the Mycoprobe Mycoplasma Detection kit (R\&D Systems). To prepare Mg-infected samples, EM42 and HeLa cells were grown on glass coverslips to $70 \%$ confluence, which was determined by haemocytometer count, and then infected $48 \mathrm{~h}$ later.

Mycoplasma-human cell infection protocol. Mg strains G37 and $1019 \mathrm{~V}$ were grown in $70 \mathrm{ml} \mathrm{SP}-4$ medium at $37{ }^{\circ} \mathrm{C}$ until early-tomid-exponential phase, as determined by individual growth curves. Surface-attached mycoplasmas were harvested by scraping into $5 \mathrm{ml}$ fresh SP-4 medium, dispersed through 25-gauge needles and passed through $0.45 \mu \mathrm{m}$ Acrodisc filters (Gelman) to minimize mycoplasma clumps. Cell monolayer cultures were inoculated at an m.o.i. of 1-7 mycoplasmas per EM42 or HeLa cell and then incubated for $30 \mathrm{~min}$ to $3 \mathrm{~h}$ at $37{ }^{\circ} \mathrm{C}$ in $5 \% \mathrm{CO}_{2}$. All experiments were repeated four times. For comparative purposes $\mathrm{Mg}$ strains deficient in adherence (Dhandayuthapani et al., 1999; Mernaugh et al., 1993; Pich et al., 2006) were grown in SP-4 broth and co-incubated at similar m.o.i. with human cells.

Immunofluorescence and confocal microscopy. Coverslips with infected cell monolayers were washed twice with PHEM buffer (60 mM PIPES, $25 \mathrm{mM} \mathrm{MgCl}_{2}, 10 \mathrm{mM}$ EGTA, pH 7.2) and fixed with $2 \%$ paraformaldehyde dissolved in PHEM buffer for $30 \mathrm{~min}$ at room temperature. Then, cells were washed twice with PHEM buffer and permeabilized with $0.1 \%$ saponin for $5 \mathrm{~min}$ (Boleti et al., 2000). After washing cells three times with PHEM buffer containing normal goat serum, cell preparations were incubated for $40 \mathrm{~min}$ with $0.1 \mathrm{ml}$ antibody directed to the C-terminal portion of adhesin P140 (rabbit anti-MgPa-III) (Svenstrup et al., 2002) at a 1/1000 dilution in PHEM with $10 \%$ normal goat serum. Rabbit antisera reactive against $\mathrm{Mg}$ proteins P110 ( $\mathrm{Mg}$ 192) and elongation factor $\mathrm{Tu}(\mathrm{Mg} 451)$ at a $1 /$ 1000 dilution were also used to detect intranuclear $\mathrm{Mg}$ protein localization. Coverslips were rinsed with PHEM and blocked with $1 \%$ normal goat serum (Gibco) for $20 \mathrm{~min}$. Then, cells were rinsed with PHEM and incubated for $40 \mathrm{~min}$ with $0.1 \mathrm{ml}$ goat anti-rabbit IgGAlexa 488 (Molecular Probes) at 1/2000 dilution in PHEM with $10 \%$ normal goat serum (Gibco). Each incubation step was performed with gentle shaking at room temperature. After the final incubation, coverslips were washed three times with PHEM buffer and mounted on slides with $25 \mu \mathrm{l}$ Vectashield Hardset mounting medium containing 4',6-diamidino-2-phenylindole (DAPI) (Vector Laboratories). For negative controls, uninfected cells were treated identically, and infected cells were incubated with normal goat serum in the absence of anti-Mg antibodies.

Images of stained cells were acquired by laser scanning confocal microscopy (LSCM) with an Olympus FV500 imaging system and IX81 microscope. The UPLANAPO $60 \times$ objective (1.4 numerical aperture) was used for all datasets, and an additional electronic zoom 
of 2 was applied. The DAPI signal was excited with a 405 Blue Diode laser and collected through a $430-460 \mathrm{~nm}$ emission filter. The Alexa 488 signal was excited with the $488 \mathrm{~nm}$ line of an argon laser and collected through a 505-525 nm emission filter. Signals from each fluorophore were collected in sequence to minimize cross-talk. Zseries datasets were generated at $0.5 \mu \mathrm{m}$ intervals from the basal to apical side of the cell monolayer using samples prepared $30 \mathrm{~min}, 1 \mathrm{~h}$ and $3 \mathrm{~h}$ post-infection. The percentage of $\mathrm{Mg}$ nuclear-positive cells was determined by counting the number of human cells with $\mathrm{Mg}$ related punctate immunofluorescence inside individual nuclei in each field and dividing by the total number of cells in that same field. Five fields were counted for each experiment, and each experiment was repeated four times. The presence of $\mathrm{Mg}$ immunofluorescence within the volume of individual nuclei was determined by evaluating $Z$-series datastacks using the multiplane form function in the Fluoview software. This function enables the datastack to be viewed in the $X Y$, $X Z$ and $Y Z$ dimensions. Inclusion of $\mathrm{Mg}$-associated immunofluorescence within the nucleus was considered positive if the DAPI signal was shown to surround the Alexa 488 signal in the $X, Y$ and $Z$ directions. Further, to determine whether the Alexa 488 signal was within the DAPI signal, a line trace was made through orthogonal sections to obtain a profile of the fluorescence distribution in both the DAPI and the Alexa 488 detection channels.

Statistical analysis. All results were expressed as the mean \pm SD. Statistical differences were determined using a non-parametric oneway ANOVA (Kruskall-Wallis) with GraphPad In-Stat3 (GraphPad Software). A value for $P<0.05$ was considered significant.

\section{RESULTS}

\section{Growth characteristics of Mg G37 and 1019V}

Mg type strain G37 has been subcultured in the laboratory for many years, and its axenic growth characteristics have been determined. In contrast, strain $1019 \mathrm{~V}$ is a recent, lowpassage isolate from a female patient, and its growth characteristics have not been examined. Therefore, growth curves were performed on both strains in parallel, so that comparable numbers of each strain at similar growth phases could be obtained for infection studies with human cell lines. The G37 strain was used at its fortieth passage while the $1019 \mathrm{~V}$ strain was at its fifth passage. $\mathrm{Mg}$ is a highly fastidious organism that grows as adherent microcolonies on the plastic surface of tissue culture flasks in liquid culture. Therefore, harvesting of bacteria requires scraping from the vessel surface of each culture and disaggregation of mycoplasmal clumps by needle passage and filtration. To evaluate bacterial growth rate as a function of time, multiple criteria were measured including spectrophotometric measurement of optical density, determination of total protein by BCA assay, quantification of mycoplasma chromosome number by real-time PCR, and use of CCU as a mycoplasma growth-associated metric.

The growth data obtained by measuring optical density gave rise to classical-appearing growth curves (Fig. 1A) that seemed nearly identical for both the G37 and 1019V isolates. The lag phase for both strains lasted approximately 2 days, followed by an exponential growth phase that spanned the period from 48 to $96 \mathrm{~h}$. Then the mycoplasmas entered into
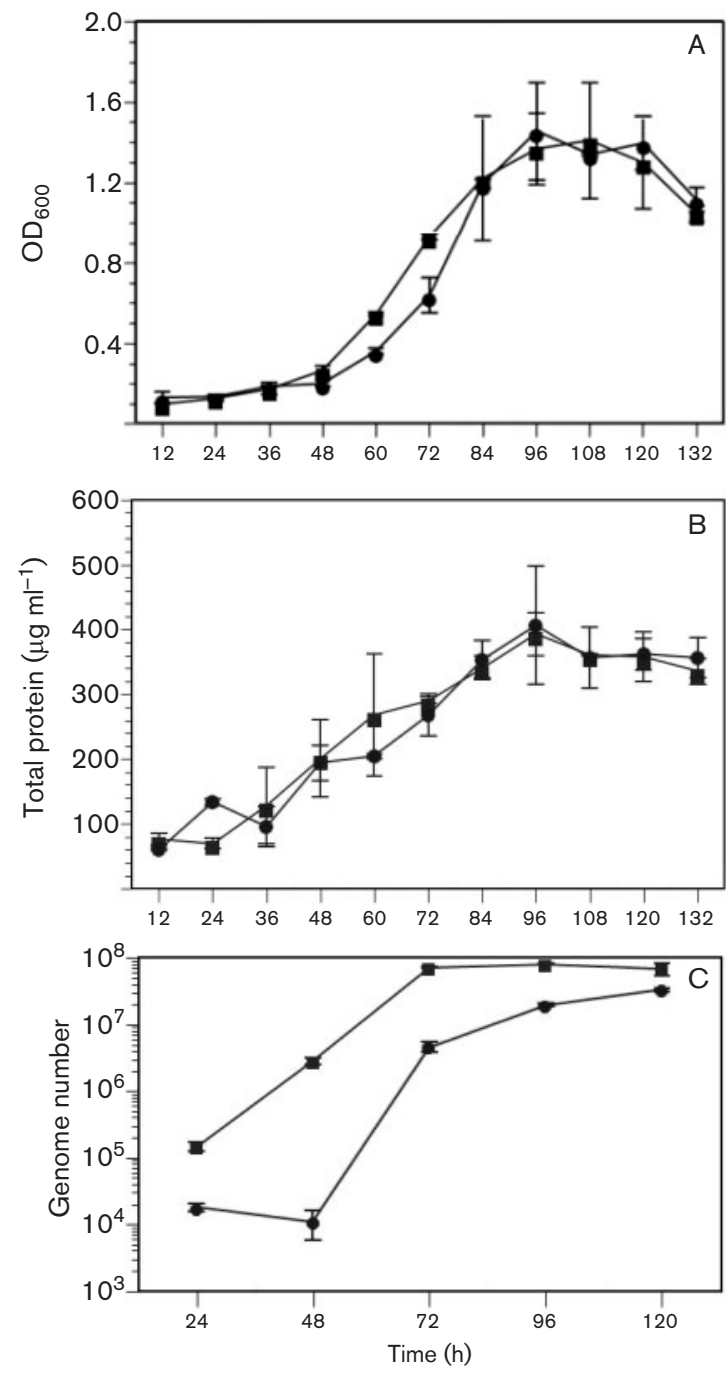

Fig. 1. Growth of Mg G37 (ם) and 1019V (@) measured by optical density (A), total protein (B), and real-time PCR (C). Samples of both strains grown axenically in SP-4 medium were analysed as detailed in Methods.

stationary phase, which ended after $4-5$ days, followed by an apparent decrease in culture optical density, consistent with bacterial lysis associated with death.

The evaluation of growth as a function of total bacterial protein for strain G37 (Fig. 1B) demonstrated that initial increases in bacterial protein occurred between 24 and $48 \mathrm{~h}$, which preceded the start of the $\mathrm{OD}_{600}$-based exponential growth phase and ended shortly after the $\mathrm{OD}_{600}$ exponential growth declined, as is common for typical bacterial growth. Early growth anomalies observed with 1019V (Fig. 1B) could represent unbalanced growth caused by the adjustment of this recently isolated, lowpassage clinical strain to axenic culture conditions. However, at later points total $1019 \mathrm{~V}$ protein calculations were consistent with G37. 
The results of quantitative PCR to enumerate $\mathrm{Mg}$ chromosomal copies are shown in Fig. 1(C). The culture conditions utilized for these assays reveal that G37 chromosome numbers increased in a linear manner until $72 \mathrm{~h}$. However, a net increase for 1019V genome numbers was delayed until $48 \mathrm{~h}$, after which mycoplasma cell replication occurred until $96 \mathrm{~h}$. Nevertheless, the genome copies for both organisms were comparable when stationary phase was reached.

The most suggestive evidence for differences in growth behaviour by the two strains was obtained when their growth dynamics were examined by CCU enumeration. As might be expected, the high-passage G37 strain appeared more adapted to in vitro conditions than the low-passage $1019 \mathrm{~V}$ strain, as judged by faster growth rates between starting inocula of $10^{6}$ and $10^{3}$. Surprisingly, we observed that G37 growth dropped off rather abruptly when lower starting densities were used. For example, G37 appeared to require at least 100 starting organisms to establish growth in broth culture (Table 1). Unexpectedly, strain $1019 \mathrm{~V}$ grew in broth culture when only 1-10 bacteria were inoculated as determined by limiting dilution assay (Table 2) consistent with colony-forming units (data not shown).

\section{Invasion by Mg of HeLa and EM42 cells}

Based upon quantitative growth curve determinations, cultures of each strain harvested at mid-exponential phase were used to infect host cells at low m.o.i. (1-7 mycoplasmas per human cell). Both EM42 and HeLa cells were co-incubated with $\mathrm{Mg}$ and, at differing postinfection times, were prepared as described in Methods. Mg-associated immunofluorescence was identified with specific antibodies directed to mycoplasma proteins P140, P110 and EF-Tu. Nuclei of human cultured cells were delineated by staining with DAPI so that the intracellular plane could be identified during optical sectioning via LSCM.
Remarkably, we observed a subset of Mg-associated immunofluorescence exhibiting an unusual subcellular localization pattern that could be clearly enumerated by LSCM. Specifically, image analysis revealed evidence of mycoplasma protein distribution within host cell nuclei (Figs 2 and 3) in a rapid and efficient manner (Fig. 4). Similar results were obtained when either G37 or 1019V isolates were examined, so while the micrographs shown here depict G37, the images obtained with $1019 \mathrm{~V}$ were indistinguishable. As shown in Fig. 2, images taken at the apical, central, and basal planes of nuclei in infected EM42 (A-C) or HeLa (D-F) cells demonstrate distinct immunofluorescence clearly included within the internal volumes. Furthermore, digital orthogonal sections through $Z$-series datasets (Figs 2 and 3 ) confirm that a portion of internalized $\mathrm{Mg}$-associated immunofluorescence is within the volume of nuclei in both EM42 (Fig. 3A-C) and HeLa (Fig. 3D-F) cells $30 \mathrm{~min}$ after infection. To confirm that the Alexa 488 signal from $\mathrm{Mg}$ was within the DAPI signal delineating host nuclei, line traces measuring pixel intensity in both channels were performed through orthogonal sections to obtain a profile of the fluorescence distribution in both DAPI and Alexa 488 detection channels (Fig. 3D-F). As demonstrated by the trace of fluorescence intensities within a selected region (Fig. 3; white box) of an infected host nucleus (Fig. 3; red box), the fluorescence distribution of Alexa 488-stained $\mathrm{Mg}$, depicted as a green line in the intensity profile graph, is fully contained within the area occupied by the DAPIstained host cell nucleus represented by the blue line in the intensity profile graph (Fig. 3). Therefore, Mg immunofluorescence in this micrograph is definitively located within the host cell nucleus. Importantly, this staining pattern is specific, as negative controls (see Methods) exhibited no evidence of $\mathrm{Mg}$-related immunofluorescence.

In order to determine the kinetics and frequency of $\mathrm{Mg}$ G37 or 1019V nuclear localization within EM42 and HeLa, a time-course infection (30, 60 and $180 \mathrm{~min}$ ) was

Table 1. Determination of growth of Mg G37 using colour-change units (CCU)

Mycoplasma CCU were determined over a period of $360 \mathrm{~h}$, from cultures inoculated with the number of bacteria shown. + indicates a change in the colour of the medium from red to yellow; - indicates no change in medium colour.

\begin{tabular}{|llllllllllllllll|}
\hline $\begin{array}{l}\text { No. of bac- } \\
\text { teria }\end{array}$ & \multicolumn{10}{c|}{ Time (h) } \\
\cline { 2 - 13 } & 24 & 48 & 72 & 96 & 120 & 144 & 168 & 192 & 216 & 240 & 264 & 288 & 312 & 336 & 360 \\
\hline $10^{6}$ & - & $+^{*}$ & & & & & & & & & & & & \\
$10^{5}$ & - & - & + & & & & & & & & & & & \\
$10^{4}$ & - & - & - & + & & & & & & & & & & \\
$10^{3}$ & - & - & - & - & - & + & & & & & & & & \\
$10^{2}$ & - & - & - & - & - & - & - & + & & & & & & \\
$10^{1}$ & - & - & - & - & - & - & - & - & - & - & - & - & - & - \\
$10^{0} \dagger$ & - & - & - & - & - & - & - & - & - & - & - & - & - & - & - \\
\hline
\end{tabular}

${ }^{\star}$ The + sign indicates the time of incubation at which initial growth occurred.

$\dagger$ Equivalent to 1 or less. 
Table 2. Determination of growth of $\mathrm{Mg} 1019 \mathrm{~V}$ using colour-change units (CCU)

Details as for Table 1.

\begin{tabular}{|c|c|c|c|c|c|c|c|c|c|c|c|c|c|c|c|}
\hline \multirow{2}{*}{$\begin{array}{l}\text { No. of } \\
\text { bacteria }\end{array}$} & \multicolumn{15}{|c|}{ Time (h) } \\
\hline & 24 & 48 & 72 & 96 & 120 & 144 & 168 & 192 & 216 & 240 & 264 & 288 & 312 & 336 & 360 \\
\hline $10^{5}$ & - & - & - & + & & & & & & & & & & & \\
\hline $10^{4}$ & - & - & - & - & + & & & & & & & & & & \\
\hline $10^{1}$ & - & - & - & - & - & - & - & - & - & + & & & & & \\
\hline $10^{0} \dagger$ & - & - & - & - & - & - & - & - & - & - & - & - & - & - & + \\
\hline
\end{tabular}

${ }^{*}$ The + sign indicates the time of incubation at which initial growth occurred.

$\dagger$ Equivalent to 1 or less.

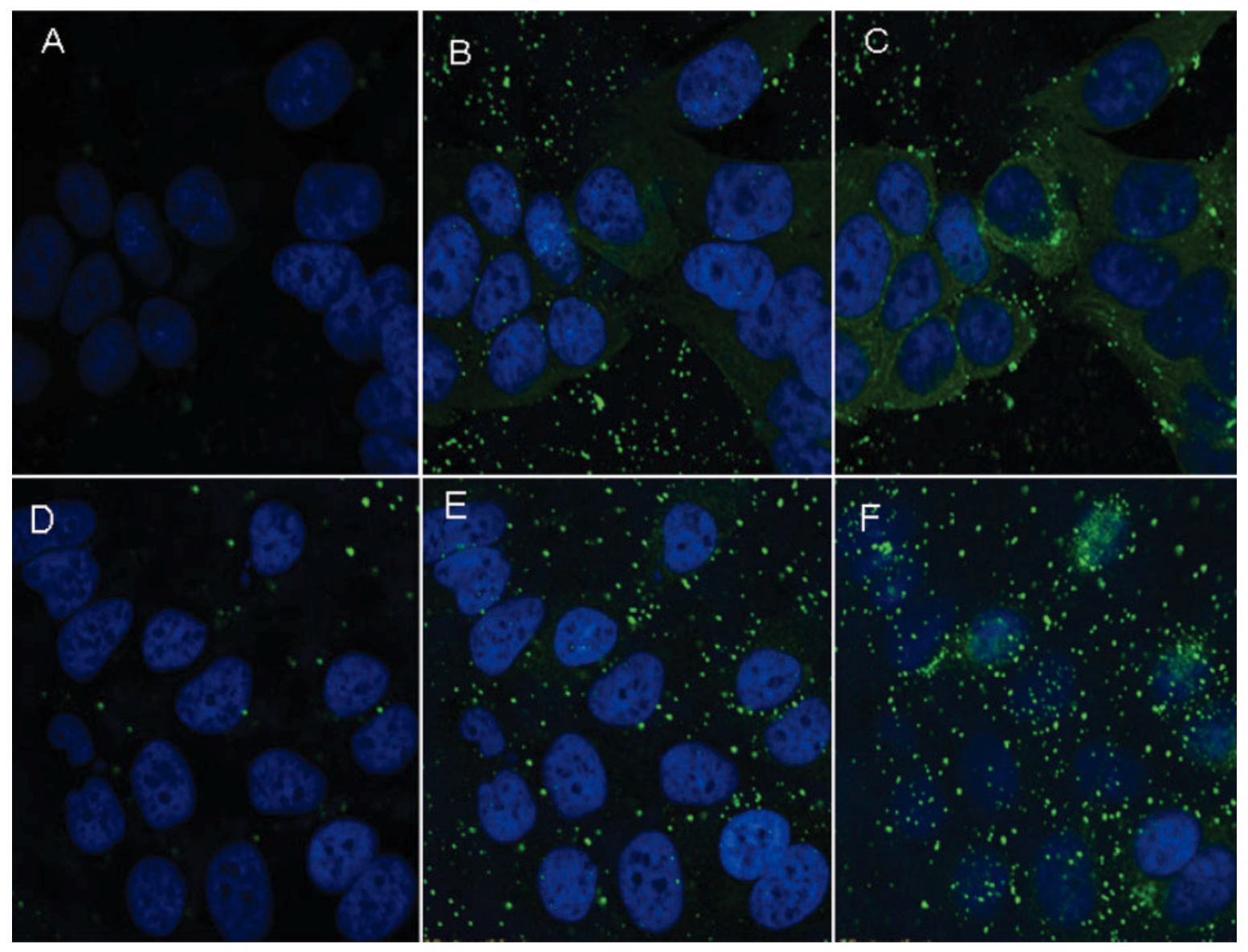

Fig. 2. LSCM of the nuclear region (blue) of Mg G37 (green)-infected uroepithelial cells at 30 min post-infection. Panels $A-C$ represent different areas (A, apical plane; $B$, central plane; $C$, basal plane) within the nuclei of the same group of Mg G37infected EM42 endometrial cells. Panels D-F represent different areas (D, apical plane; E, central plane; $F$, basal plane) within the nuclei of the same group of Mg G37-infected HeLa cervical epithelioid cells. The DAPI-stained host nuclei appear blue while the green-appearing Mg G37 were visualized using primary rabbit antibody directed to the C-terminal region of P140 adhesin and Alexa 488-conjugated secondary antibody. 

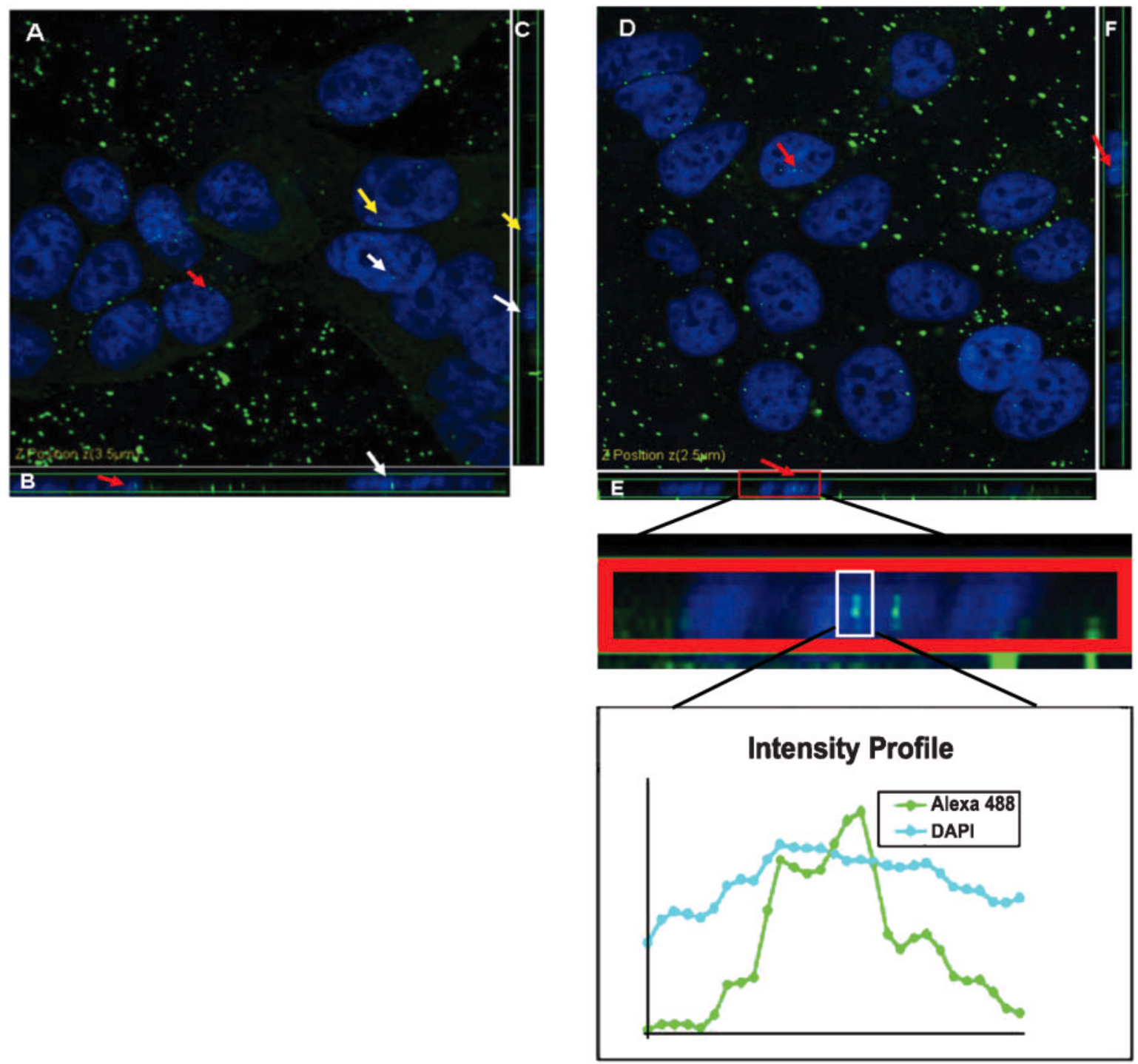

Fig. 3. LSCM of nuclear region (blue) of Mg G37 (green)-infected uroepithelial cells at 30 min post-infection. Digital orthogonal sections through Z-series datasets confirm that Mg G37-associated immunofluorescence is within the volume of EM42 (A-C) and HeLa (D-F) cell nuclei. Images show the central section of individual nuclei of EM42 (A) and HeLa (D) cells and extended views of the horizontal ( $B$ and $E$ ) and vertical ( $C$ and F) Z-projections of EM42 and HeLa cells, respectively. Colours of arrows (red, yellow and white) indicate the localization of $\mathrm{Mg}$ immunofluorescence in the horizontal and vertical Zprojections. The small red-boxed portion of $(\mathrm{E})$ is enlarged (large red box) to better delineate DAPI and Alexa 488 . The white box defines the nuclear area through which the trace of relative intensities of green $(\mathrm{Mg})$ and blue (host nucleus) pixels was determined. Data are graphically depicted in the Intensity Profile, where all green pixels representing Mg are contained within the blue pixels defining the host nucleus.

performed and samples fixed and fluorescently stained (Fig. 4). For example, the percentage of EM42 cells containing $\mathrm{Mg}$ G37-associated immunofluorescence within their nuclei increased from approximately $15 \%$ by 30 min post-infection to $40 \%$ by $1 \mathrm{~h}$ and $60 \%$ by $3 \mathrm{~h}$ post-infection. Mg strain $1019 \mathrm{~V}$ was detected in approximately $30 \%$ of EM42 cell nuclei at $30 \mathrm{~min}$ and $1 \mathrm{~h}$ postinfection, and in $50 \%$ at $3 \mathrm{~h}$ post-infection. This rapid intranuclear localization event was observed in all four independent experiments conducted, with at least half of all infected cells containing evidence of intranuclear mycoplasma proteins (P140, P110 and EF-Tu) within $3 \mathrm{~h}$ after invasion. Similar intranuclear targeting occurred when HeLa cells were used (data not shown). Importantly, $\mathrm{Mg}$ mutants deficient in adherence revealed less than $1 \%$ nuclear-associated immunofluorescence using antisera reactive against P140, P110 and EF-Tu (data not shown). 


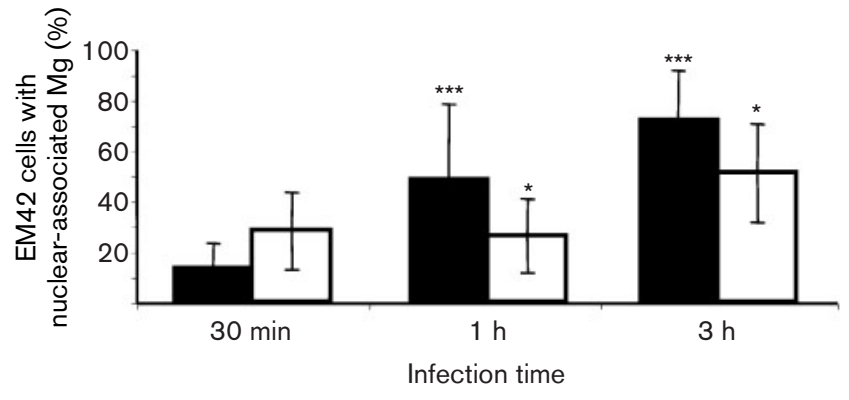

Fig. 4. Percentage of human EM42 cells with nuclear-associated Mg G37 and 1019V immunfluorescence at $30 \mathrm{~min}, 1 \mathrm{~h}$ or $3 \mathrm{~h}$ post-infection. Black bars, Mg G37; white bars, Mg 1019V; ${ }^{\star} P<0.05 ;{ }^{* *} P<0.001$.

\section{DISCUSSION}

In the present study, we monitored $\mathrm{Mg}$-host cell interactions comparing two distinct mycoplasma strains that differ in terms of both the amount of axenic passage they have experienced since initial isolation and sequence heterogeneity within adherence-associated proteins P140 and P110. Care was taken to evaluate their growth features, such that comparable input numbers of similarly grown mycoplasmas (Fig. 1) were co-incubated with human nonphagocytic cultured cells of urogenital origin. The lowpassage isolate $1019 \mathrm{~V}$ grew more slowly in broth compared to G37, when mycoplasma cultures were started with a high inoculum density (Tables 1 and 2). However, both isolates reached comparable numbers by stationary phase (Fig. 1). Surprisingly, the multiple-passage and laboratoryadapted strain G37 required a starting inoculum at least two orders of magnitude higher than strain 1019V (Tables 1 and 2). These starting density-related features of G37 are probably the result of inadvertent adaptation to high starting densities commonly used in the laboratory in order to obtain large numbers of bacteria for investigative purposes. In contrast, strain $1019 \mathrm{~V}$ may benefit in the clinical setting from being able to efficiently outgrow from a single cell while being transmitted to a new host or colonizing the urogenital tract as an ascending urogenital infection. Despite the subtle axenic growth differences observed between the two strains, time-course analysis using LSCM to identify intracellular mycoplasmas revealed the striking phenotype of intranuclear localization of $\mathrm{Mg}$ proteins within $30 \mathrm{~min}$, and in at least half of host cells $3 \mathrm{~h}$ post-infection (Figs 2, 3 and 4).

Our results indicate that both high- and low-passage $\mathrm{Mg}$ strains behaved similarly in terms of the host-mycoplasma interaction, although studies with other mycoplasmas have revealed pronounced strain-dependent differences. For example, distinct Mycoplasma fermentans strains exhibited different rates of infection in HeLa cells, severity of tissue damage, and localization (Stadtlander et al., 1993). Mycoplasma gallisepticum high- or low-passaged strains differed significantly in their entry into HeLa cells (Winner et al., 2000). Extension of these findings to the $M$. gallisepticum chicken infection model demonstrated a correlation between the in vitro invasive potential of specific mycoplasma strains and their mucosal penetration and virulence in vivo (Much et al., 2002). Thomas et al. (2003) described varied adherence rates when Mycoplasma bovis isolates that differed in the number of in vitro passages were used to infect a variety of cultured host cells. Despite past precedent for altered host function as a consequence of laboratory passage, we observed little difference between the high-passage G37 and low-passage $1019 \mathrm{~V}$ strains using the cellular interaction phenotype of nuclear localization. However, this is only one cellassociation-related phenotype, and it is possible that G37 and $1019 \mathrm{~V}$ strains will display differences in host interaction when additional criteria are examined. Interestingly, Mg mutants derived from G37 and deficient in host-cell interactions demonstrated markedly reduced internalization and perinuclear/intranuclear localization capabilities, reinforcing the invasive properties of clinically relevant wild-type $\mathrm{Mg}$ strains and their relationship to disease pathogenesis.

The invasive potential of $\mathrm{Mg}$ described herein has been reported previously for this and other human mycoplasma pathogens. Jensen et al. (1994) observed internalization of Mg G37 in Vero monkey kidney cells, while Mernaugh et al. (1993) described Mg G37 entry into human lung fibroblasts. In addition, the highly invasive Mycoplasma penetrans (Mpen) was observed to attain cytoplasmic and perinuclear localization in WI-38 cells (Baseman et al., 1995). Furthermore, Mycoplasma pneumoniae (Mp), which is the closest relative to $\mathrm{Mg}$, achieves cytoplasmic and perinuclear localization in WI-38 (Baseman et al., 1995) by $2 \mathrm{~h}$, and a similar localization was reported for this pathogen within the human hepatocyte cell line Hep-G2 (Meseguer et al., 2003). Yavlovich et al. (2004) observed Mp internalization in human lung carcinoma A549 cells but not in HeLa epithelial cells. Finally, evidence for a nuclear locale for some mycoplasma species has been suggested. For example, examination of tissue from non-human primates fatally infected with $M$. fermentans identified bacteria inside Kupffer cells via electron microscopy (Lo et al., 1993). Subcellular fractionation of HEp-2 cells persistently infected with $\mathrm{Mp}$ or Mpen demonstrated that viable mycoplasmas could be grown from nuclear fractions (Dallo \& Baseman, 2000). The observation that a subfraction of intracellular Mpen associated with the nucleus, in the context of reports that host DNA damage occurs within Mpen-persistently infected cells, may imply that mycoplasma nuclear association could have virulence consequences (Feng et al., 1999).

Therefore, the observed perinuclear localization and cofractionation results reported previously suggest that mycoplasmas associate with the host nucleus. However, our study distinguishes itself from earlier work by the finding of internalization in uroepithelial-derived cells as 
early as $30 \mathrm{~min}$, with a high percentage of host cells infected by $3 \mathrm{~h}(>50 \%)$ as adjudged by nuclear localization immunofluorescence. Furthermore, the nature of the nuclear association reported herein based upon the intranuclear distribution of three distinct $\mathrm{Mg}$ proteins is fully consistent with $\mathrm{Mg}$ and its products breaching the nuclear membrane.

The disease-related biological consequences of mycoplasma internalization have not been established. However, there is an association between mycoplasma internalization and the traits of persistence and drug resistance observed in cultured host cells (Dallo \& Baseman, 2000). As stated above, $\mathrm{Mg}, \mathrm{Mp}$ and Mpen survived in cultured cells for at least 6 months, with replication observed in the presence of antibiotic concentrations that should kill extracellular bacteria. Therefore, persistence correlated with invasion. The intracellular phenotype of $\mathrm{Mg}$ is also clinically relevant, as host cells derived directly from patients were found to be heavily parasitized intracellularly based upon confocal immunoanalysis and transmission immunoelectron microscopy of clinical samples from infected women (Blaylock et al., 2004). Therefore, we speculate that the invasive potential of $\mathrm{Mg}$ is substantial, especially given our finding that intranuclear evidence of mycoplasmas suggests an ability to transit from the extracellular environ through two host membranes (cytosolic and nuclear), further reinforcing the clinically observed persistence of this pathogen.

The nuclear localization observed for $\mathrm{Mg}$ is apparently without precedent for other bacterial pathogens. This is not to imply that other bacterial pathogens do not exploit the host nucleus by the targeting of protein effectors and toxins. For example, Mycobacterium tuberculosis delivers nucleoside-diphosphate kinase to the host cell nucleus, where this enzyme mediates in situ DNA damage that contributes to host cell death (Saini et al., 2004). Shigella flexneri translocates two type III effectors into the host cell nucleus, and they alter cellular function by modulating select signal transduction pathways (Zurawski et al., 2006). The cytolethal distending toxin of specific pathogenic bacteria exhibits nuclear translocation and leads to host cell DNA damage and cell cycle arrest (McSweeney \& Dreyfus, 2004). Here, we describe the rapid delivery of three distinct $\mathrm{Mg}$ proteins and possibly the entire bacterium into the nucleus, which seems to present novel challenges. The exact mechanisms for mycoplasma nuclear-associated entry and the potential signal transduction and genetic and pathogenetic consequences associated with this biological manoeuvre remain to be elucidated. However, initial events in the Mg-human cell invasive process could lead to alterations in host cell membrane function, evidence of early-stage loss of cell viability and nuclear membrane vulnerability leading to $\mathrm{Mg}$ intranuclear penetration. Also, the intense perinuclear association of $\mathrm{Mg}$ reported earlier (Baseman et al. 1995; Dallo \& Baseman, 2000) could result in intranuclear entrapment of $\mathrm{Mg}$ during host cell division and nuclear membrane disruption and re-formation.
With the establishment of the mycoplasma-host cell interaction model system utilized in this study, future investigations are readily feasible, which should demystify these biological associations and provide unique insights as to how this smallest of self-replicating pathogens can successfully circumvent the immune response and navigate through host cell structures. Specifically, how do this bacterium and its products exploit host cell function to traffic to the nucleus? Virus trafficking to the nucleus seems the most related pathogenic system, and the extensive body of work on viral nuclear trafficking should serve as a guide for future Mg studies. Our future studies will focus on the identification of host cytoskeletal elements that are needed to impart the observed $\mathrm{Mg}$ nuclear tropism and the characterization of disrupters of normal cellular architecture trafficking that alter $\mathrm{Mg}$ nuclear association. The association of host nuclear protein complexes and domains in relation to the location of intranuclear mycoplasma may also provide insights into potential entry mechanisms exploited by Mg. While previous studies support the viability and replicative potential of nuclear-associated mycoplasmas (Dallo \& Baseman, 2000), it still remains to be determined if nuclear-associated $\mathrm{Mg}$ replicate in this locale and how nuclear-associated mycoplasmas might segregate within dividing host cells. Both transcriptional analysis of nuclear fractions and live imaging analysis of infected cells should help to address the intranuclear viability and replication issues associated with $\mathrm{Mg}$ parasitism.

\section{ACKNOWLEDGEMENTS}

The study described was supported by Award Number U19 AI045429 and AI41017 from the National Institute of Allergy and Infectious Diseases (NIAID). The content is solely the responsibility of the authors and does not necessarily reflect the official views of NIAID or the National Institutes of Health. Images were generated in the Core Optical Imaging Facility, which is supported by UTHSCSA, NIH-NCI P30 CA54174 (San Antonio Cancer Institute), NIH-NIA P30 AG013319 (Nathan Shock Center) and (NIH-NIA P01AG19316). The authors are very grateful to Dr Oxana Musatovova for guidance and insight with quantitative PCR methods, Drs H. F. Svenstrup and G. Christiansen for the gift of rMgPa domain III polyclonal antibody, Dr T. R. Kannan for suggestions for growth experiments and manuscript content, and S. S. Bubeck for statistical computations and figure preparation.

\section{REFERENCES}

Baseman, J. B. \& Tully, J. G. (1997). Mycoplasmas: sophisticated, reemerging, and burdened by their notoriety. Emerg Infect Dis 3, 21-32.

Baseman, J. B., Lange, M., Criscimagna, N. L., Giron, J. A. \& Thomas, C. A. (1995). Interplay between mycoplasmas and host target cells. Microb Pathog 19, 105-116.

Baseman, J. B., Cagle, M., Korte, J. E., Herrera, C., Rasmussen, W. G., Baseman, J. G., Shain, R. \& Piper, J. M. (2004). Diagnostic assessment of Mycoplasma genitalium in culture-positive women. J Clin Microbiol 42, 203-211. 
Blaylock, M. W., Musatovova, O., Baseman, J. G. \& Baseman, J. B. (2004). Determination of infectious load of Mycoplasma genitalium in clinical samples of human vaginal cells. J Clin Microbiol 42, 746-752.

Boleti, H., Ojcius, D. M. \& Dautry-Varsat, A. (2000). Fluorescent labelling of intracellular bacteria in living host cells. J Microbiol Methods 40, 265-274.

Cohen, C. R., Nosek, M., Meier, A., Astete, S. G., Iverson-Cabral, S. Mugo, N. R. \& Totten, P. A. (2007). Mycoplasma genitalium infection and persistence in a cohort of female sex workers in Nairobi, Kenya. Sex Transm Dis 34, 274-279.

Dallo, S. F. \& Baseman, J. B. (2000). Intracellular DNA replication and long-term survival of pathogenic mycoplasmas. Microb Pathog 29, 301-309.

Desai, N. N., Kennard, E. A., Kniss, D. A. \& Friedman, C. I. (1994), Novel human endometrial cell line promotes blastocyst development. Fertil Steril 61, 760-766.

Dhandayuthapani, S., Rasmussen, W. G. \& Baseman, J. B. (1999). Disruption of gene $m g 218$ of Mycoplasma genitalium through homologous recombination leads to an adherence-deficient phenotype. Proc Natl Acad Sci U S A 96, 5227-5232.

Falk, L., Fredlund, H. \& Jensen, J. S. (2004). Symptomatic urethritis is more prevalent in men infected with Mycoplasma genitalium than with Chlamydia trachomatis. Sex Transm Infect 80, 289-293.

Feng, S. H., Tsai, S., Rodriguez, J. \& Lo, S. C. (1999). Mycoplasmal infections prevent apoptosis and induce malignant transformation of interleukin-3-dependent 32D hematopoietic cells. Mol Cell Biol 19, 7995-8002.

Fraser, C. M., Gocayne, J. D., White, O., Adams, M. D., Clayton, R. A., Fleischmann, R. D., Bult, C. J., Kerlavage, A. R., Sutton, G. \& other authors (1995). The minimal gene complement of Mycoplasma genitalium. Science 270, 397-403.

Jensen, J. S., Blom, J. \& Lind, K. (1994). Intracellular location of Mycoplasma genitalium in cultured Vero cells as demonstrated by electron microscopy. Int J Exp Pathol 75, 91-98.

Lo, S. C., Wear, D. J., Shih, J. W., Wang, R. Y., Newton, P. B., III \& Rodriguez, J. F. (1993). Fatal systemic infections of nonhuman primates by Mycoplasma fermentans (incognitus strain). Clin Infect Dis 17 (Suppl. 1), S283-S288.

McSweeney, L. A. \& Dreyfus, L. A. (2004). Nuclear localization of the Escherichia coli cytolethal distending toxin CdtB subunit. Cell Microbiol 6, 447-458.

Mernaugh, G. R., Dallo, S. F., Holt, S. C. \& Baseman, J. B. (1993). Properties of adhering and nonadhering populations of Mycoplasma genitalium. Clin Infect Dis 17 (Suppl. 1), S69-S78.

Meseguer, M. A., Alvarez, A., Rejas, M. T., Sanchez, C., Perez-Diaz, J. C. \& Baquero, F. (2003). Mycoplasma pneumoniae: a reducedgenome intracellular bacterial pathogen. Infect Genet Evol 3, 47-55.

Much, P., Winner, F., Stipkovits, L., Rosengarten, R. \& Citti, C. (2002), Mycoplasma gallisepticum: influence of cell invasiveness on the outcome of experimental infection in chickens. FEMS Immunol Med Microbiol 34, 181-186.

Musatovova, O., Herrera, C. \& Baseman, J. B. (2006). Proximal region of the gene encoding cytadherence-related protein permits molecular typing of Mycoplasma genitalium clinical strains by PCR-restriction fragment length polymorphism. J Clin Microbiol 44, 598-603.

Pich, O. Q., Burgos, R., Ferrer-Navarro, M., Querol, E. \& Pinol, J. (2006). Mycoplasma genitalium $m g 200$ and $m g 386$ genes are involved in gliding motility but not in cytadherence. Mol Microbiol 60, 1509-1519.

Poddar, A. S., Kim, J. G., Gill, K. P., Bates, B. N., Santanam, N., Rock, J. A., Murphy, A. A. \& Parthasarathy, S. (1998). Generation and characterization of a polyclonal antipeptide antibody to human glycodelin. Fertil Steril 69, 543-548.

Razin, S. \& Tully, J. G. (1983). Methods in Mycoplasmology, vol. 1. New York: Academic Press.

Saini, A. K., Maithal, K., Chand, P., Chowdhury, S., Vohra, R., Goyal, A., Dubey, G. P., Chopra, P., Chandra, R. \& other authors (2004). Nuclear localization and in situ DNA damage by Mycobacterium tuberculosis nucleoside-diphosphate kinase. J Biol Chem 279, 50142-50149.

Stadtlander, C. T., Watson, H. L., Simecka, J. W. \& Cassell, G. H. (1993). Cytopathogenicity of Mycoplasma fermentans (including strain incognitus). Clin Infect Dis 17 (Suppl. 1), S289-S301.

Stein, M. A. \& Baseman, J. B. (2006). The evolving saga of Mycoplasma genitalium. Clin Microbiol Newsl 28, 41-48.

Svenstrup, H. F., Nielsen, P. K., Drasbek, M., Birkelund, S. \& Christiansen, G. (2002). Adhesion and inhibition assay of Mycoplasma genitalium and M. pneumoniae by immunofluorescence microscopy. J Med Microbiol 51, 361-373.

Taylor-Robinson, D., Gilroy, C. B., Thomas, B. J. \& Hay, P. E. (2004). Mycoplasma genitalium in chronic non-gonococcal urethritis. Int $\mathrm{J}$ STD AIDS 15, 21.

Thomas, A., Sachse, K., Farnir, F., Dizier, I., Mainil, J. \& Linden, A. (2003). Adherence of Mycoplasma bovis to bovine bronchial epithelial cells. Microb Pathog 34, 141-148.

Tully, J. G., Taylor-Robinson, D., Cole, R. M. \& Rose, D. L. (1981). A newly discovered mycoplasma in the human urogenital tract. Lancet 1, 1288.

Wang, R. Y., Grandinetti, T., Shih, J. W., Weiss, S. H., Haley, C. L., Hayes, M. M. \& Lo, S. C. (1997). Mycoplasma genitalium infection and host antibody immune response in patients infected by HIV, patients attending STD clinics and in healthy blood donors. FEMS Immunol Med Microbiol 19, 237-245.

Wikstrom, A. \& Jensen, J. S. (2006). Mycoplasma genitalium: a common cause of persistent urethritis among men treated with doxycycline. Sex Transm Infect 82, 276-279.

Winner, F., Rosengarten, R. \& Citti, C. (2000). In vitro cell invasion of Mycoplasma gallisepticum. Infect Immun 68, 4238-4244.

Yavlovich, A., Tarshis, M. \& Rottem, S. (2004). Internalization and intracellular survival of Mycoplasma pneumoniae by non-phagocytic cells. FEMS Microbiol Lett 233, 241-246.

Zurawski, D. V., Mitsuhata, C., Mumy, K. L., McCormick, B. A. \& Maurelli, A. T. (2006). OspF and OspC1 are Shigella flexneri type III secretion system effectors that are required for postinvasion aspects of virulence. Infect Immun 74, 5964-5976.

Edited by: C. Citti 